\title{
Taste aversion induced by an histidine-free amino acid load*
}

\author{
D. A. BOOTH and P. C. SIMSON \\ Psychology Department, University of Birmingham, P.O. Box 363, Birmingham B15 2TT, England
}

\begin{abstract}
Protein-free diet flavored with saccharin or salt was presented to rats following a single intragastric administration of a histidine-devoid, but otherwise balanced, amino acid mixture. A control load was paired with the alternate flavor on another day. When they were subsequently given a choice of flavors, the rats preferred the control flavor to the one paired with the deficient load.
\end{abstract}

Rats acquire a specific aversion to an odor in concentrations too low to be tasted, if the odor is incorporated in a protein-free diet consumed within a few hours of gastric loading with an amino acid mixture which is nutritionally balanced except for the omission of histidine (Booth \& Simson, 1971; Simson \& Booth, 1973a, b, 1974). It can be argued that gustatory stimuli are likely to be more effectively acquired cues to the aversive consequences of ingestion. Olfactory cues may have weaker effects on intake because they are better suited to the acquired control of the approach to food rather than its consumption. On the other hand, in the multiple-stimulus situations commonly faced by omnivores, intake of a particular foodstuff is primarily determined by selection of meal components, rather than by persistence in consumption of a single foodstuff. Furthermore, olfactory and textural cues provide a far richer basis for discrimination than do gustatory stimuli. Whether stronger or weaker, and whether more or less usable, taste aversions to amino-acid-deficient diets would be expected to occur no less confidently than the odor aversions already demonstrated. This expectation was tested in the work reported here.

\section{METHOD}

\section{Animals}

The rats were 16 males of an albino Sprague-Dawley-derived strain bred at the University of Sussex School of Biological Sciences, caged individually with room lights on from 8:30 a.m. to $8: 30$ p.m. Before the experiment, they had been maintained with free access to water and laboratory chow. Body weights at the start of experimentation were in the range of $120-160 \mathrm{~g}$.

\section{Diets and Gastric Loads}

To facilitate the rat's discrimination of modest levels of flavoring added to a solid foodstuff, the experimental diets were prepared in agar gel. The solid base nutrient, either chow powder or dextrin, was mixed with gel in the proportion of $1 \mathrm{~g} / \mathrm{ml}$ of $1 \%$ agar and $0.25 \%$ benzoic acid. When a flavor was added, it was either sodium chloride or sodium saccharin added to final concentrations of $0.6 \%$ or $0.05 \%$, respectively. The histidine-free, but otherwise balanced, amino acid mixture was, in proportions by weight: leu 11.9 , ile 5.5 , val 5.2 , met 4.3 , thr 6.5 , try 3.5 , phe 6.8 , lys 12.8 , arg 7.8 , gly 5.5 , glu 27.5 , with bases as their hydrochlorides, glutamate as the monosodium salt,

*Work supported by a grant from the Medical Research Council, U.K. and stereoisomers in the $\mathrm{L}$ form. The mixture was given as $1 \mathrm{~g}$ in $10 \mathrm{ml}$ of water. The control load was an approximately iso-osmotic $2.7 \%$ sodium chloride solution.

\section{Procedure}

The rats were first adapted to agar diets and to intensive feeding and absorption by a few cycles of deprivation. Chow-gel diet was presented from noon to 6 p.m. on successive days, with no food available in the intervening periods.

At noon on the following day, the deprived animals were gastrically intubated with either saline or amino acids at a dose of $50 \mathrm{ml} / \mathrm{kg}$ body weight. Half the group received one load, half the other. Flavored dextrin-gel diet was then presented to each rat for $20 \mathrm{~min}$, half of each subgroup being given sweet-flavored diet, and half being given salty-flavored diet. A second 20-min presentation of the same flavored diet was given at 2 p.m.

The same general load-flavor pairing procedure was followed the next day, but each rat received its alternate load and flavor.

A series of 20-min flavor tests without gastric intubation was carried out at noon on each of the subsequent 3 days. Half of the rats in each training sequence of loads and flavors were given single-stimulus tests for 2 days and a double-stimulus test on the 3 rd day. The other half of the group had the double-stimulus test first, followed by the 2 days of single-stimulus tests. In each sub-group, salty dextrin gel was given to half the rats on the first single-stimulus test day, with sweet diet on the 2 nd day; the other half had the reverse sequence. In the double-stimulus test, each rat was given a choice between a salty sample and a sweet sample of dextrin-gel diet.

\section{RESULTS}

\section{First Access on Loading Days}

In the first 20-min period of access to flavored dextrin diet following gastric loading, intake on the day of loading with histidine-free amino acid mixture did not differ systematically (Table 1) or reliably (Table 2) from intake on the day of administration of the control saline load in the same animals. Compared between animals on the first loading day or on the day of the control load, intakes of sweet and salty samples of the diet did not differ systematically either (Table 1).

\section{Second Access on Loading Days}

In contrast, during the second 20-min period of access to diet of the same flavor $2 \mathrm{~h}$ later, intake after loading with amino acids was markedly lower than intake after saline loading (Tables 1 and 2). There was no reliable interaction of this effect with the dietary flavor, either 
Table 1

Mean Intakes (Grams) of Flavored Protein-Free Diet

\begin{tabular}{|c|c|c|c|c|c|c|c|c|c|}
\hline \multirow[b]{2}{*}{$\begin{array}{l}\text { Gastric Load } \\
\text { on Day } 1 \\
\end{array}$} & \multirow[b]{2}{*}{$\begin{array}{c}\text { Taste on } \\
\text { Day } 1\end{array}$} & \multicolumn{2}{|c|}{$\begin{array}{c}\text { Day of Amino } \\
\text { Acid Load }\end{array}$} & \multicolumn{2}{|c|}{$\begin{array}{c}\text { Day of Control } \\
\text { Load }\end{array}$} & \multicolumn{2}{|c|}{$\begin{array}{l}\text { Single-Stimulus } \\
\text { Tests }\end{array}$} & \multicolumn{2}{|c|}{$\begin{array}{l}\text { Double-S timulus } \\
\text { Tests }\end{array}$} \\
\hline & & $\begin{array}{c}\text { First } \\
\text { Access }\end{array}$ & $\begin{array}{l}\text { Second } \\
\text { Access }\end{array}$ & $\begin{array}{c}\text { First } \\
\text { Access }\end{array}$ & $\begin{array}{l}\text { Second } \\
\text { Access }\end{array}$ & $\begin{array}{c}\text { Amino Acid } \\
\text { Paired } \\
\text { Taste }\end{array}$ & $\begin{array}{l}\text { Control } \\
\text { Taste }\end{array}$ & $\begin{array}{c}\text { Amino Acid } \\
\text { Paired } \\
\text { Taste }\end{array}$ & $\begin{array}{l}\text { Control } \\
\text { Taste }\end{array}$ \\
\hline Amino Acids & $\begin{array}{l}\text { Sweet } \\
\text { Salty }\end{array}$ & $\begin{array}{l}4.3 \\
4.9\end{array}$ & $\begin{array}{l}1.1 \\
1.4\end{array}$ & $\begin{array}{l}3.1 \\
6.1\end{array}$ & $\begin{array}{l}4.0 \\
4.5\end{array}$ & $\begin{array}{l}7.8 \\
5.9\end{array}$ & $\begin{array}{l}8.6 \\
7.0\end{array}$ & $\begin{array}{l}5.9 \\
2.8\end{array}$ & $\begin{array}{l}6.8 \\
4.2\end{array}$ \\
\hline Control & $\begin{array}{l}\text { Sweet } \\
\text { Salty }\end{array}$ & $\begin{array}{l}6.6 \\
6.4\end{array}$ & $\begin{array}{l}1.5 \\
0.2\end{array}$ & $\begin{array}{l}5.4 \\
4.8\end{array}$ & $\begin{array}{l}5.3 \\
2.3\end{array}$ & $\begin{array}{l}6.6 \\
3.0\end{array}$ & $\begin{array}{l}8.6 \\
5.5\end{array}$ & $\begin{array}{l}3.1 \\
1.2\end{array}$ & $\begin{array}{l}2.1 \\
3.1\end{array}$ \\
\hline
\end{tabular}

in the intake values for different rats on one day or in the intake differences between days in the same rats. A tendency for intake to be lower in the second access period than in the first was highly reliable on the amino acid day $(\mathrm{p}<.001)$ but was not reliable on the control day $(\mathrm{p}>.1)$.

\section{Subsequent Days Without Loads}

Intake tests for acquired specific gustatory preferences, unconfounded by effects of recent gastric loads, demonstrated the existence of an aversion to whichever taste had been paired with the histidine-free amino acid load, relative to the taste paired with the control load (Tables 1 and 2). The observed degree of aversion was similar in single-stimulus and double-stimulus tests, at least on a ratio measure (Table 2), although the variation was greater in the double-stimulus tests because of three grossly aberrant rats in the subgroup tested on Day 3.

There was no sign of extinction of the acquired gustatory control of intakes during the repeated testing without loads on Days 3-5; aversion in single-stimulus tests was as strong in the subgroup which was given these tests on Days 4 and 5 (mean intake ratio, -0.20 ) as in the subgroup tested on Days 3 and $4(-0.17)$, and was no less strong in the subgroup given double-stimulus tests on Day $5(-0.29)$ than in the other subgroup tested on Day $3(-0.06)-$ neither pair of ratio values differing significantly ( $p s>.2$ by Mann-Whitney $\mathrm{U}$ tests and uncorrelated $t$ tests).

A similar pattern of somewhat weaker effects was observed in a partial replication of this experiment in which an unflavored chow-cornflour-gel diet was presented briefly during the daytime before the training days and also overnight throughout training and testing, and in which only one $15-\mathrm{min}$ period of access to a flavored sample of the cornflour-gel diet was given following the administration of each gastric load.

\section{DISCUSSION}

Relatively large volumes of iso-osmotic loads of amino acid mixture and sodium chloride would not be expected to affect food intake differentially immediately following administration at a time when mechanical and colligative gastrointestinal effects are dominant. After $2 \mathrm{~h}$, however most of the load has been absorbed (Simson \& Booth,1974) and metabolic effects are likely to dominate. The suppression of intake at about $2 \mathrm{~h}$ after administration of the histidine-free amino acid load was also observed in earlier experiments in which the diets were odorized (Booth \& Simson, 1971; Simson \& Booth, 1973). Although the present data do not distinguish between anorexia and specific aversion, previous work has indicated that this intake suppression after $2 \mathrm{~h}$ is not a general loss of appetite but is the first expression of an acquired aversion to the specific odor which has been present since loading (Simson \& Booth, 1974). Thus, the suggestion is that the absorption of a histidine-deficient mixture of amino acids, within $2 \mathrm{~h}$ of experiencing a salient taste, established a specific aversion to that taste and that this aversion depressed intake in the second access period in the present experiment.

If this early effect is indeed an expression of acquired gustatory aversion, the strength of the aversion seen in the later single-stimulus tests indicates good retention over $24-72 \mathrm{~h}$. In any case, considerable resistance to extinction was evidenced by the persistence of the specific aversion throughout the series of tests for acquired gustatory control of intake.

The relative strengths of the gustatory and olfactory aversions induced by a histidine-deficient load remain to be determined. The present procedure differs in many respects from that used in the earlier olfactory aversion

Table 2

Training and Testing for Gustatory Aversion

\begin{tabular}{lrrc}
\hline & \multicolumn{3}{c}{ Food Intake Ratio } \\
\cline { 2 - 5 } \multicolumn{1}{c}{ Intake Sessions } & Mean & $\begin{array}{c}\text { SE of } \\
\text { Mean }\end{array}$ & $\begin{array}{c}\mathrm{p} \text { by } \\
\mathrm{t} \text { Test }\end{array}$ \\
\hline Intubation Days & & & \\
$\quad$ First-Access Periods & 0.06 & 0.07 & $>.2$ \\
$\quad$ Second-Access Periods & -0.44 & 0.16 & $<.02$ \\
Test Days & & & \\
$\quad$ Single-Stimulus Tests & -0.19 & 0.04 & $<.01$ \\
$\quad$ Double-Stimulus Tests & -0.18 & 0.10 & .1 \\
\hline
\end{tabular}

Note-Food intake ratios are: intake of the flavored diet associated with the histidine-devoid amino acid load minus intake of the flavored diet associated with the control load, divided by the sum of the intakes. The simple difference of intakes showed the same pattern of effects, with identical $p$ values by Wilcoxon tests and correlated $t$ tests. 
studies, and so the intake difference and ratio values obtained here should not be compared with earlier values. Indeed, there is presently no fully satisfactory procedure for providing olfactory and gustatory cues under precisely equivalent conditions of stimulus duration, salience, and response contingency.

\section{REFERENCES}

Booth, D. A., \& Simson, P. C. Food preferences acquired by association with variations in amino acid nutrition. Quarterly Journal of Experimental Psychology, 1971, 23, 135-145.
Simson, P. C., \& Booth, D. A. Olfactory conditioning by association with histidine-free or balanced amino acid loads in rats. Quarterly Journal of Experimental Psychology, 1973a, 25, 354-359.

Simson, P. C., \& Booth, D. A. Effects of CS-US interval on the conditioning of odour preferences by amino acid loads. Physiology \& Behavior, $1973 \mathrm{~b}, 11,801-808$.

Simson, P. C., \& Booth, D. A. The rejection of a diet which has been associated with a single administration of an histidine-free amino acid mixture. British Journal of Nutrition, 1974, 31, 285-296.

(Received for publication March 26, 1974; revision received May $2,1974$. .) 